\title{
USING AIR FOR INCREASING THE DEPTH OF THE FLUE GAS HEAT RECOVERY
}

\author{
Victor Bespalov ${ }^{1, a}$, Leonid Beljaev ${ }^{1}$, Denis Melnikov ${ }^{1}$ \\ ${ }^{1}$ Tomsk Polytechnic University, 634050 Tomsk, Russia
}

\begin{abstract}
The methods of flue gas heat recovery have been reviewed and carried out their effectiveness analysis. Revealed a theoretical limit of flue gas deep heat recovery and suggested possible ways to achieve them. The possibility of using air as a heated medium is discussed in more detail.
\end{abstract}

\section{Introduction}

Since the gas-fired boilers begun using massively, the flue gas heat recovery task has acquired special importance [1]. The thermal energy contained in the flue gases can be divided into two parts.

The first is associated with high temperature exhaust gases. This heat is utilized by decrease gases temperature and useful heating another medium (water, air, etc.). Flue gas temperature in this case can be reduced to the dew point of water vapor contained in the flue gases.

The second is the latent heat of water vapor condensation. Latent heat utilization requires the water vapor condensation, and the obtained heat heats the water, air or other medium. In conventional terminology such heat recovery called deep utilization.

The natural gas mainly consists of methane, and combustion products contain a large amount of water vapor. The flue gases moisture content is between 150 to 108 grams per kilogram of dry gas ( $g / k g . d . g)$, depending on the excess air ratio $(\alpha=1 \div 1.4)$. Heat recovery process by cooling the flue gases to the dew point precedes the water vapor condensation. Obtained heat amount depends on the initial flue gases temperature. It is usually quite high, ranging from $130^{\circ} \mathrm{C}$ to $170^{\circ} \mathrm{C}$ and above. The temperature of the water vapor dew point is $56^{\circ} \mathrm{C}$ for the excess air ratio $\alpha=1,2$. If the flue gas flow is $1 \mathrm{~m}^{3} / \mathrm{s}$, then can be obtained by cooling about $100 \div 160 \mathrm{~kW}$, which corresponds to $3 \div 6 \%$ additional heat capacity [2].

When cooling the flue gas below the dew point temperature, the water vapor begins to condense. The recovery depth will be determined by the condensed moisture amount, i.e. the difference between the flue gas moisture content before and after heat recovery. The initial moisture content and dew point depends only on the combusted gas composition and excess air ratio. Theoretically the lower limit of the water vapor condensation temperature is $0^{\circ} \mathrm{C}$. At lower temperatures the condensate will be freezing. The flue gas moisture content at $0^{\circ} \mathrm{C}$ is $3.7724(\mathrm{~g} / \mathrm{kg} . \mathrm{d} . \mathrm{g})$. Theoretically, the maximum possible amount of condensed moisture will be determined by the difference between the initial moisture content and the moisture content at $0^{\circ} \mathrm{C}$. The maximum theoretical condenser capacity is

${ }^{a}$ Corresponding author : vic@tpu.ru 


\section{MATEC Web of Conferences}

from 472 to $364 \mathrm{~kW}$ depending on the excess air ratio at the flue gas flow $1 \mathrm{~m}^{3} / \mathrm{s}$. Consequently, an additional produced power capacity is $13 \%$ of the boiler capacity, only due to water vapor condensation in outgoing flue gases $[1,2]$. The total additional boiler thermal capacity can be from 13 to $20 \%$.

\section{Research methodologies}

In practice, the condensers cannot condense all water vapor. To estimate the process depth is convenient to use two coefficients. Flue gas dehumidifying coefficient $K_{d}$ is equal to the ratio condensate flow to its maximum theoretical value. Here, the determining factor is the final flue gas temperature equal to the dew point temperature of the residual water vapor. This temperature determines the final moisture content, the condensate flow rate and the condenser thermal capacity. Heat recovery depth coefficient $K_{r}$, defined as the ratio real thermal capacity of heat recovery device to the theoretical one (the maximum possible). This coefficient is more revealing to compare the heat recovery units, because takes into account the heat loss from the condensate and residual water vapor. The optimal final flue gases temperature is located about $20^{\circ} \mathrm{C}$, which corresponds approximately to the dehumidifying coefficient 0.9 . Reducing the final temperature below $20^{\circ} \mathrm{C}$ does not lead to a significant increase in the condensate flow and the power growth [2].

According to the operating principle the flue gas heat recovery condensers are divided into contact and surface $[1,3]$. An overview publication about applied heat recovery units shows that the flue gas cooling is usually close to a temperature $35 \div 45^{\circ} \mathrm{C}$. Depth dehumidifying is not more than 0,7 . This is due to using the water as a heated medium $[3,4]$. When using the return water of heating systems its temperature should be lower than $40^{\circ} \mathrm{C}$, that is contrary to the heating systems temperature schedule (150-70, 90-65), used in our country. Such schemes are available for low potential heating systems used in some foreign countries. Heating the water for domestic hot water is rarely used due to the low water consumption and a large daily non-uniformity. Most installations for deep heat recovery heated the additional water for the heating systems from 10 to $40^{\circ} \mathrm{C}[5,6]$.

The large heat recovery depth is achieved only by using another heated medium, which may operate with a negative working temperature, for example cold air. Most Russian regions have a negative temperature in winter. Monthly average winter temperature drops below $-15^{\circ} \mathrm{C}$ for the Siberian regions. The temperature graphs of the condensing heat recovery units using air and water are shown in Figure 1.

As can be seen from the graphs, the flue gases are cooled by air much more. It is possible to achieve a high heat recovery depth coefficient, close to the 1 .
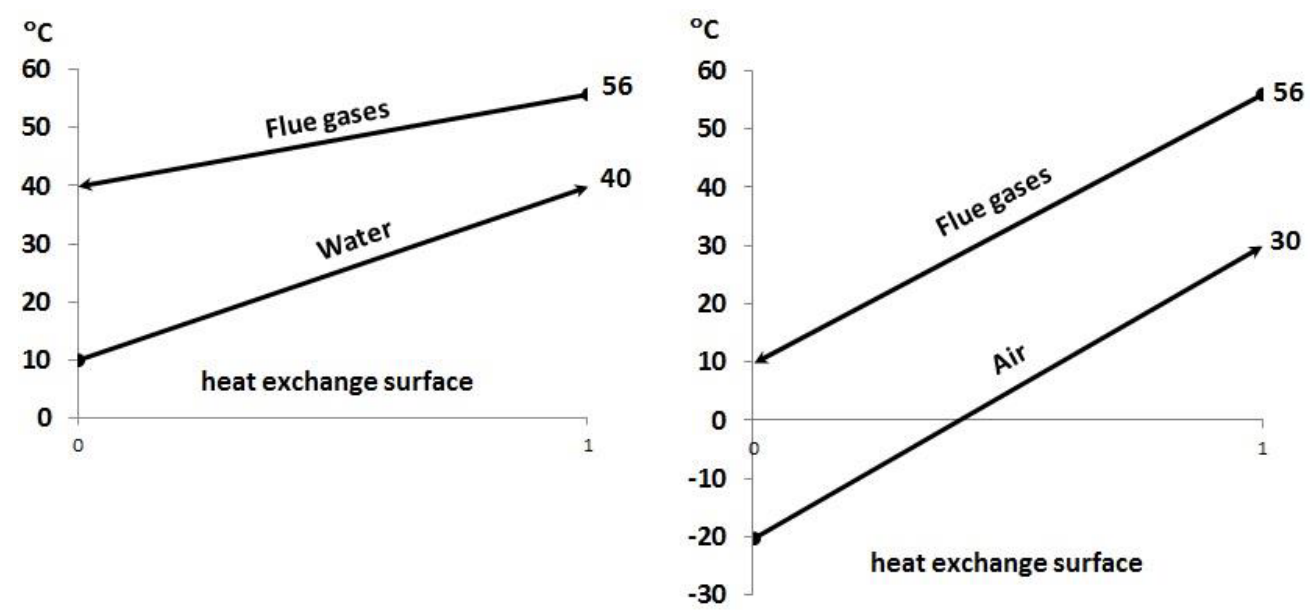

Figure 1. Using water and air as a heating media 
The advantage of using air is that its final temperature about $30^{\circ} \mathrm{C}$ is quite sufficient for industrial premises air heating. Part of the heated air is fed to the boiler to provide the gas combustion process. Balance calculations show that heat recovery from the flue gas flow rate $1 \mathrm{~m}^{3} / \mathrm{s}$ requires the air flow rate $7.5 \mathrm{~m}^{3} / \mathrm{s}$. The combustion process requires the air flow rate about $0.75 \mathrm{~m}^{3} / \mathrm{s}$. The remaining heated air heats industrial premises, and fully covers enterprise own needs for heat. Produced overpressure eliminates the cold air inflow into the premises.

The proposed approach disadvantage is the fact that such a large amount of heated air is not always possible to use fully. For example, in some modular gas-fired boiler-houses, where there are no large amount of premises for air heating. In this case it is expedient to use for heat recovery only a part of the flue gases, calculated for high temperature preheat the air only for burning process. However, even in such a case it is possible to increase the gas-fired boiler efficiency at $2 \div 3 \%$.

\section{Results}

The simplest and most efficient design for such a condensing heat recovery unit is a plate-type heat exchanger - condenser. The technology of deep heat recovery has been developed (Figure 2), it allows to cool the flue gases to the optimum temperature about $20^{\circ} \mathrm{C}$ and best fully use the water vapor condensation heat.

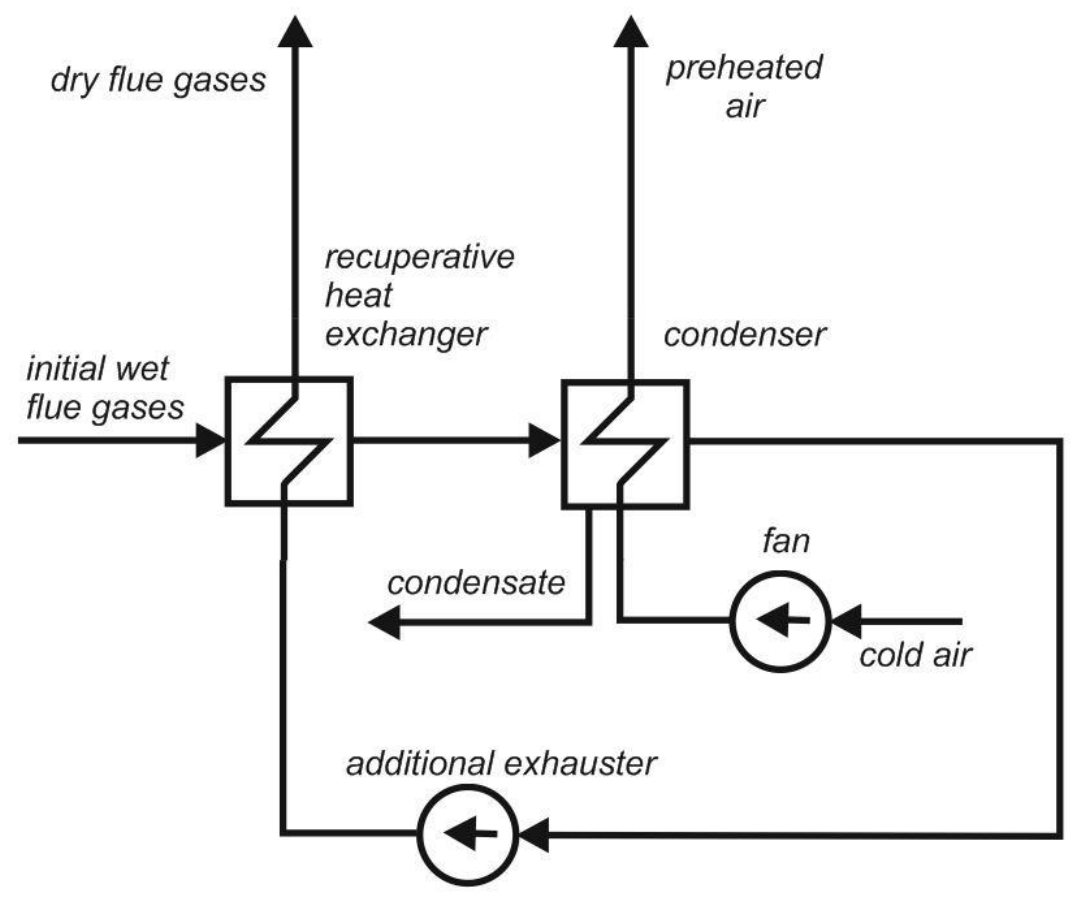

Figure 2. The technology of flue gas deep heat recovery

Initial flue gases are pre-cooled in the recuperative gas-gas surface plate-type heat exchanger by heating the dry flue gases to prevent the possible water vapor condensation into the flue and chimney. In the gas-air plate-type condenser occurs further cooling the flue gases and water vapor condensation by heating the air. Air is supplied to the condenser by fan. Additional exhauster compensates the aerodynamic drag into the flues, heat exchanger and condenser.

According to the above technology was held designing of some installations for different gas boiler capacities. The total boiler improving the efficiency by cooling the flue gases and the water vapor condensation is about $13 \div 20 \%$. Payback period is less than a year.

Energy and economic characteristics of installations for several gas boilers are shown in Table 1. 


\section{MATEC Web of Conferences}

Table 1. Energy and economic characteristics of installations

\begin{tabular}{|c|c|c|c|}
\hline & $\begin{array}{l}\text { Powerful boiler } \\
\text { CHP. }\end{array}$ & District boiler & $\begin{array}{c}\text { Local hot water } \\
\text { boiler }\end{array}$ \\
\hline \multicolumn{4}{|l|}{ A gas-fired boiler. } \\
\hline Thermal power, $M W$ & 350 & 26 & 1,3 \\
\hline Combustion air flow rate, $\mathrm{m}^{3} / \mathrm{s}$ & 116 & 8,8 & 0,44 \\
\hline Flue gas flow rate, $\mathrm{m}^{3} / \mathrm{s}$ & 133 & 10 & 0,5 \\
\hline Flue gas temperature, ${ }^{\circ} \mathrm{C}$ & 130 & 150 & 170 \\
\hline $\begin{array}{l}\text { The water vapor dew point temperature in the } \\
\text { flue gas, }{ }^{\circ} \mathrm{C}\end{array}$ & 55 & 56 & 56 \\
\hline Flue gas flow rate for heat recovery, $\mathrm{m}^{3} / \mathrm{s}$ & $33(25 \%)$ & $10(100 \%)$ & $0,5(100 \%)$ \\
\hline \multicolumn{4}{|c|}{ Installation of flue gas heat recovery. } \\
\hline Thermal power (recovered heat), $M W$ & 10 & 4 & 0,24 \\
\hline Air flow rate, $\mathrm{m}^{3} / \mathrm{s}$ & 194 & 70 & 4,5 \\
\hline Air heating, ${ }^{\circ} \mathrm{C}$ & from -15 to +26 & from -20 to +28 & from -20 to +22 \\
\hline Exhaust flue gas temperature, ${ }^{\circ} \mathrm{C}$ & 86 & 70 & 62 \\
\hline $\begin{array}{l}\text { The water vapor dew point temperature in the } \\
\text { exhaust gas, }{ }^{\circ} \mathrm{C}\end{array}$ & 30 & 10 & 3 \\
\hline Condensate flow rate, $\mathrm{kg} / \mathrm{s}$ & 3,3 & 1,2 & 0,07 \\
\hline Heat exchange surface area, $m^{2}$ & 8265 & 2880 & 180 \\
\hline Capital investments, $m \ln . R u b$. & 27 & 9 & 0,7 \\
\hline Annual cost savings, $m \ln . R u b$. & 27,5 & 10 & 0,8 \\
\hline Improving the boiler efficiency on & $2,3 \%$ & $15 \%$ & $15 \%$ \\
\hline
\end{tabular}

\section{Conclusion}

- Existing technologies and deep heat recovery units surface- and contact-type use the water as a heated medium. Heat recovery depth coefficient of such installations is about $0.6 \div 0.7$. Using the air as a heated medium reduces the final dew point temperature of the flue gases to the limit values and allows to get the depth coefficient close to 1 .

- Maximum efficiency is achieved by using air for gas boilers and CHP plants located on the industrial enterprises territory, which have the ability to carry out the air heating of industrial premises.

- Different versions of deep heat recovery units developed under the current technology have the payback period less than a year. 


\section{References}

1. R. Thompson, R. Goldstick, R. Vogt, American Flame Research Committee, 281 (1981)

2. V. Bespalov, Power engineering of Tatarstan, 2, 32 (2015).

3. A. Kudinov, V. Antonov A., Y. Alekseev, J. Therm. Eng., 1, 65 (2000).

4. A. Garjaev, E. Tseplyaeva, Sur l'efficacite energetique, 1, 187 (2003)

5. X. Shi, D. Che, B. Agnew, J. Gao, Int. J. Heat Mass Transfer, 54, 606 (2011)

6. K. Jeong, M. Kessen, H. Bilirgen, E. Levy, Int. J. Heat Mass Transfer, 53, 2361 (2010) 